\title{
Intracranial Chondroma. Report of Two Cases and Review of the Literature
}

\author{
Daniel Lacerte, Francois Gagné and Michel Copty
}

\begin{abstract}
Introduction: Chondromas are rare intracranial tumors. The authors present two cases of intracranial intradural chondroma, one originating from the falx cerebri and the other from the dura mater of the convexity. Method and Results: Diagnostic procedures, including magnetic resonance imaging, and surgical findings are described. In both cases, pre-operative diagnosis could have been at least suspected, and the tumor was completely removed, without recurrence after a follow-up of many years. The pathogenesis and pathological findings are discussed, and cases from the literature are reviewed. Conclusion: Benign intradural chondroma has a good prognosis, with no recurrence after surgical excision in most cases.
\end{abstract}

RÉSUMÉ: Présentation de deux cas de chondrome intracrânien et revue de la littérature. Introduction: Les auteurs présentent 2 cas exceptionnels de chondrome intracranien intradural, une tumeur intracranienne particulièrement rare. Un cas originait de la faux du cerveau et l'autre de la dure-mère de la convexité. Méthode et Résultats: Les données d'imagerie, incluant la résonance magnétique nucléaire, de même que les données chirurgicales sont présentées. Dans les deux cas, le diagnositc pré-opératoire pouvait être fortement suspecté, et une excision complète de la lésion a été pratiquée, sans signe de récidive après une période de suivi de nombreuses années. La pathogénèse et la pathologie sont discutées, et les auteurs font une revue brève des cas de la littérature. Conclusion: Le chondrome intradural bénin est une tumeur à bon pronostic avec un risque très faible de récurrence après excision chirurgicale complète.

Can. J. Neurol. Sci. 1996; 23: 132-137

Chondromas are rare intracranial tumors, representing $0.2-$ $0.3 \%$ of all primary intracranial tumors. ${ }^{1,2}$ They usually arise from the synchondrosis at the base of the skull., ${ }^{1,3-6}$ Less frequently they arise from the dura (convexity or falx), ${ }^{7-20}$ from inside the ventricles ${ }^{21-25}$ or the cerebral parenchyma without apparent dural attachment. ${ }^{26-29}$ Their suspected development from embryonic remnants of the primordial cartilage in the synchondrosis at the base of the skull may explain their predilection for this location. However, the histogenesis of supratentorial tumors originating from the falx, the dura mater or brain parenchyma is not well understood. In the present report two dural chondromas are described. Their diagnostic criteria are discussed. An attempt is made to correlate the pathological and radiological features. Finally, the authors compare their findings with those reported in the literature.

\section{Case Report}

\section{Patient 1}

This patient was a 22-year-old man with a 1 month history of focal motor seizures, with convulsions involving the left arm and leg. He had no headache or other symptoms of increased intracranial pressure. The clinical examination on admission revealed normal physical and neurological findings. Plain skull films demonstrated a ring-like calcification in the right frontoparietal area, without any sign of increased intracranial pressure (Figure 1). A computed tomographic scan showed a large hyperdense intracranial space-occupying lesion, located in the right fronto-parietal area near the midline, with a calcified implantation base on the falx (Figure 1). There was no oedema, and neither significant mass effect nor enhancement. A right external and internal carotid angiogram revealed an avascular lesion with displacement of normal blood vessels.

A craniotomy was performed, and the opening of the dura-mater disclosed an intradural extracerebral tumor. The tumor was completely removed including its attachment to the falx. The tumor was easily cleaved from the brain surface. The post-operative course was eventless. The last CT scan was done in 1990, 5 years after the operation, and showed no evidence of recurrence. Pathologic examination revealed a $5.5 \times 4.4 \times 3.8 \mathrm{~cm}$ firm mass with a slightly lobulated surface. Section showed a lobulated greyish-white semilucent surface. Calcifications were rather extensive mostly close to the basal membranous surface. Histologically the lesion was made of nodules of perfectly mature cartilaginous tissue with thin sparsely cellular conjunctive and vascular strands (Figure 1). Calcifications developed within the cartilaginous matrix, as normally happens in chondromas. Bone formation was also focally extensive, with areas of hematopoietic activity.

\section{Patient 2}

This 32-year-old woman was brought in for evaluation of headache and slight weakness and fine tremor of the left arm. The neurological

From the Department of Neurosurgery (DL, MC), and Neuropathology (FG), Hôpital de l'Enfant-Jésus, Québec.

RECEIVED MAY 23, 1995. ACCEPTED IN FINAL, FORM OCTOBER 12, 1995.

Reprint requests to: Daniel Lacerte, M.D., Hôpital de l'Enfant-Jésus, 1401, $18^{\mathrm{c}}$ rue, Québec, Québec, Canada G1J 1ZA 
examination revealed slight weakness on the left side. The skull films showed a $2 \times 1 \mathrm{~cm}$ area of hyperostosis of the inner table on the right frontal area (Figure 2). The CT scan showed a very large and well circumscribed lesion in the right frontal area, with an hypodense central part and a peripheral hyperdense enhancing part (Figure 2). A pre-operative angiogram revealed vascular displacements without tumoral blush, in agreement with an extra-axial avascular lesion. An MRI was done, showing a large lesion with well-defined margins and a right posterior frontal dural implantation. The $\mathrm{Tl}$-weighted sequence showed a markedly hypointense central part and a slightly hypointense peripheral part (Figure 2). The proton time and T2-weighted sequences showed a hyperintense signal in the central part and a nearly isointense heterogenous signal in the peripheral part, with a thin hypointense margin and no oedema (Figure 2 ).

A right frontal craniotomy was performed, and the tumor was totally removed. It originated from the dura-mater of the convexity, without evidence of brain invasion. The dural attachment was easily cleaved from the skull, without any evidence of dural transgression or bone invasion. The last CT scan was done 4 years later, in 1991, with no sign of recurrence. Grossly, the lesion measured close to $8 \times 6 \times 6 \mathrm{~cm}$ and weighed 124 grams. The dural attachment measured $6 \times 5.3 \mathrm{~cm}$. The surface was discretely lobulated. The cut surface was the same as that of Patient 1 , except for a slightly eccentric deep, soft, depressed, sharply limited but irregularly shaped zone of yellowish-white tissue (Figure 3). The main histologic picture was that of mature hyaline cartilaginous tissue. In rather extensive areas, lacunae were not so well developed and cellularity was slightly denser, but these, in absence of nuclear atypia, larger nuclei, binucleated cells and mitosis, were not considered as indicative of even borderline malignancy. The soft sub-central area described grossly was not made of necrotic tissue but of a very loose-textured connective vascular tissue, identical with that normally present in chondromas, ${ }^{30}$ separating the cartilaginous matrix lobules (Figure 3 ). This tissue was made of widely separated fibroblasts and small bloodvessels. The wide intercellular spaces were most often unstained; in some areas they were occupied by a slightly acidophilic homogeneous material with no polysaccharidic staining. This connective tissue thus appeared as mainly edematous. Liquid loss from the cut surface explained its tendency to shrink and collapse, then appearing as nearly cystic.

\section{Discussion}

Intracranial chondromas are rare lesions. Mapstone et al. ${ }^{13}$ in 1983 reviewed the literature and found 120 cases of intracranial chondromas, of which 29 originated outside the cranial base (dura, falx, cerebral parenchyma or choroid plexus). We found 18 additional cases in our analysis of the world literature, increasing the total number of published cases to 47 , including our 2 cases. About $70 \%$ of the cases originated from the dura mater, the remaining cases (30\%) were located inside the brain parenchyma or the choroid plexus (Table 1). The tumors at the convexity were located more often in the fronto-parietal area (Table 1).

The histogenesis of intracranial chondromas and chondrosarcomas has been debated. Those originating from the basal synchondrosis are believed to arise from embryonic remnants of chondrogenic cells in such areas. ${ }^{1,4,6,31}$ The origin of dural chondromas and chondrosarcomas is, at first glance, more speculative. Hypotheses include development from heterotopic chondrocytes, ${ }^{5,32}$ metaplasia of meningeal fibroblasts ${ }^{1,7,31}$ or perivascular mesenchymal tissue ${ }^{26)}$ and origin from meningeal connective tissue as a result of cartilaginous activation of fibroblasts by trauma of inflammation. ${ }^{27}$

Russell \& Rubinstein ${ }^{5}$ and Sheithauer \& Rubinstein, ${ }^{33}$ favour an origin from pluripotential mesenchymal cells or from their more differentiated descendants abnormally present in meningeal tissue. Nevertheless, the recent observation by Katayama et al..$^{34}$ of a meningeal chondrosarcomatous tumor
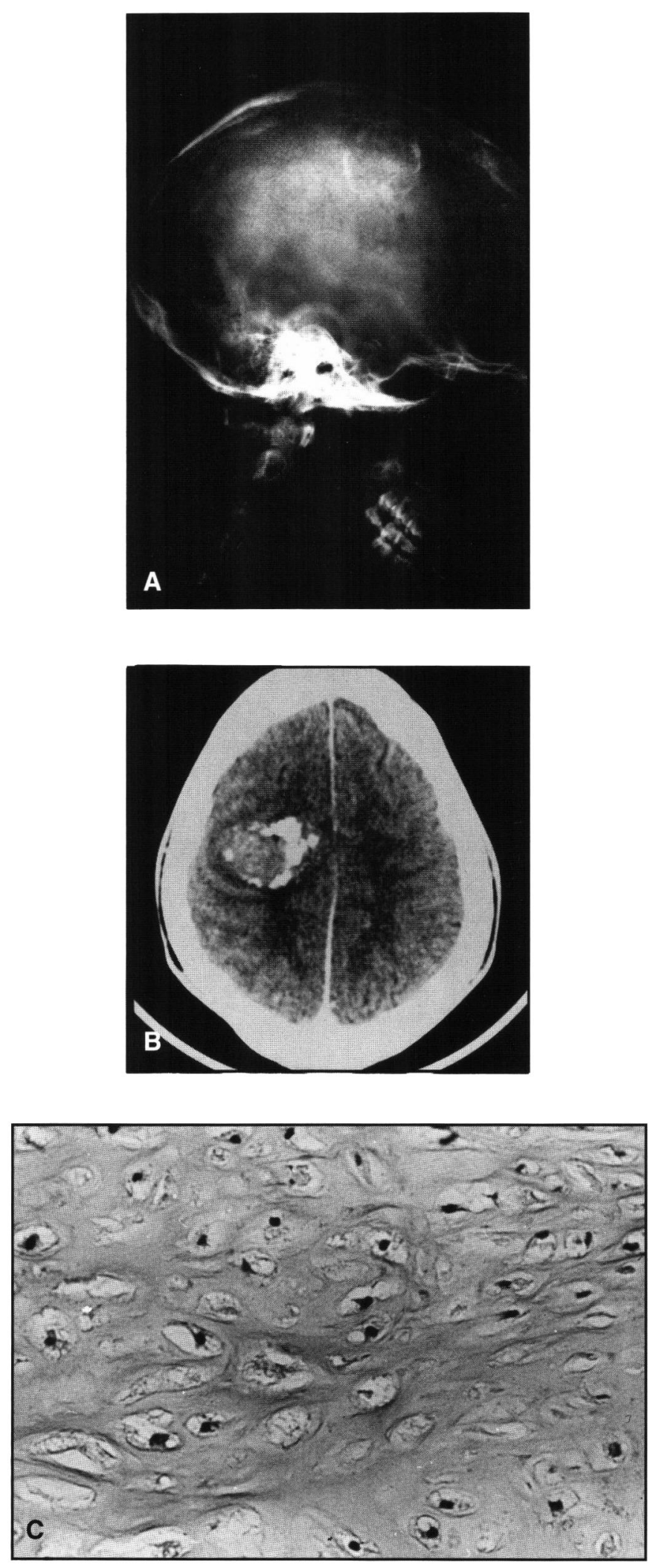

Figure 1: Patient 1. A) Lateral skull radiograph showing a ring-like calcification in the right frontoparietal area. B) CT scan with contrast enhancement showing the lesion with a calcified implantation base on the falx, and little enhancement. C) Representative photomicrograph. microscopic appearance of tumor from Patient 1 , with well differentiated chondrocytes. $H \& E \times 160$. 

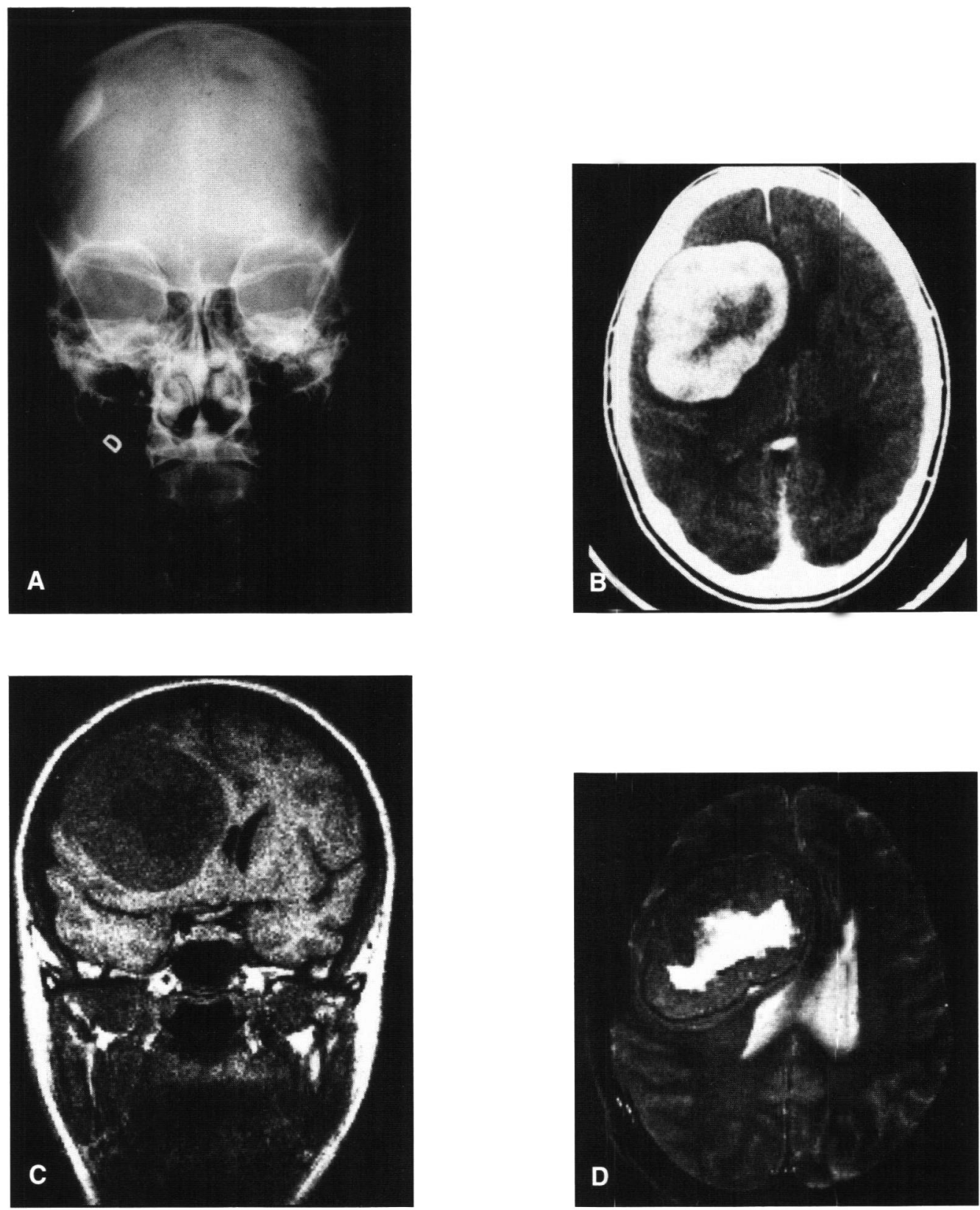

Figure 2: Patient 2. A) AP skull radiograph showing hyperostosis of the inner table of the skull. B) CT scan with contrast enhancement showing the large lesion with hypodense central part and peripheral enhancing part. Coronal $T I$-weighted magnetic resonance image $C$ ) showing the very hypointense central part and slightly hypointense peripheral part. On axial T2-weighted sequence D) the central part became highly hyperintense and the peripheral part isointense. Gadolinium was not used (not available in our center in 1987).

associated with meningocytic differentiation has revived the hypothesis proposed by Cushing \& Eisenhardt (cited by the authors),$^{34}$ according to which at least an occasional meningeal cartilaginous tumor might originate from meningocytes through a form of metaplastic differentiation. Katayama et al. have found a few similar reported cases. The same process probably explains Russell \& Rubinstein's ${ }^{5}$ observations of transitional aspects between meningioma and haemangiopericytoma. By analogy, such a metaplastic phenomenon can explain the occurrence of cartilaginous differentiation in glial tumors. ${ }^{35}$

The clinical context of chondroma is different from that of a much more frequent meningeal tumor, the meningioma, which most commonly occurs in the fourth through sixth decades of life with a peak incidence at 45 years, ${ }^{36}$ and which is twofold more frequent in women than in men. ${ }^{36}$ For intracranial chondroma, we found in our review a mean age of 30 years at presentation, and a slight male predominance $(60 \%$ versus $40 \%)$ (Table 2). This seems to imply a different biological context and pathogenesis. Clinically, patients often present with a long standing history of headache progressing toward a more obvious picture of increased intracranial pressure, seizures (more often focal motor seizures), or a progressive lateralized deficit which varies according to tumor location. This is not suprising if we consider the slow-growing nature of these tumors, their very 

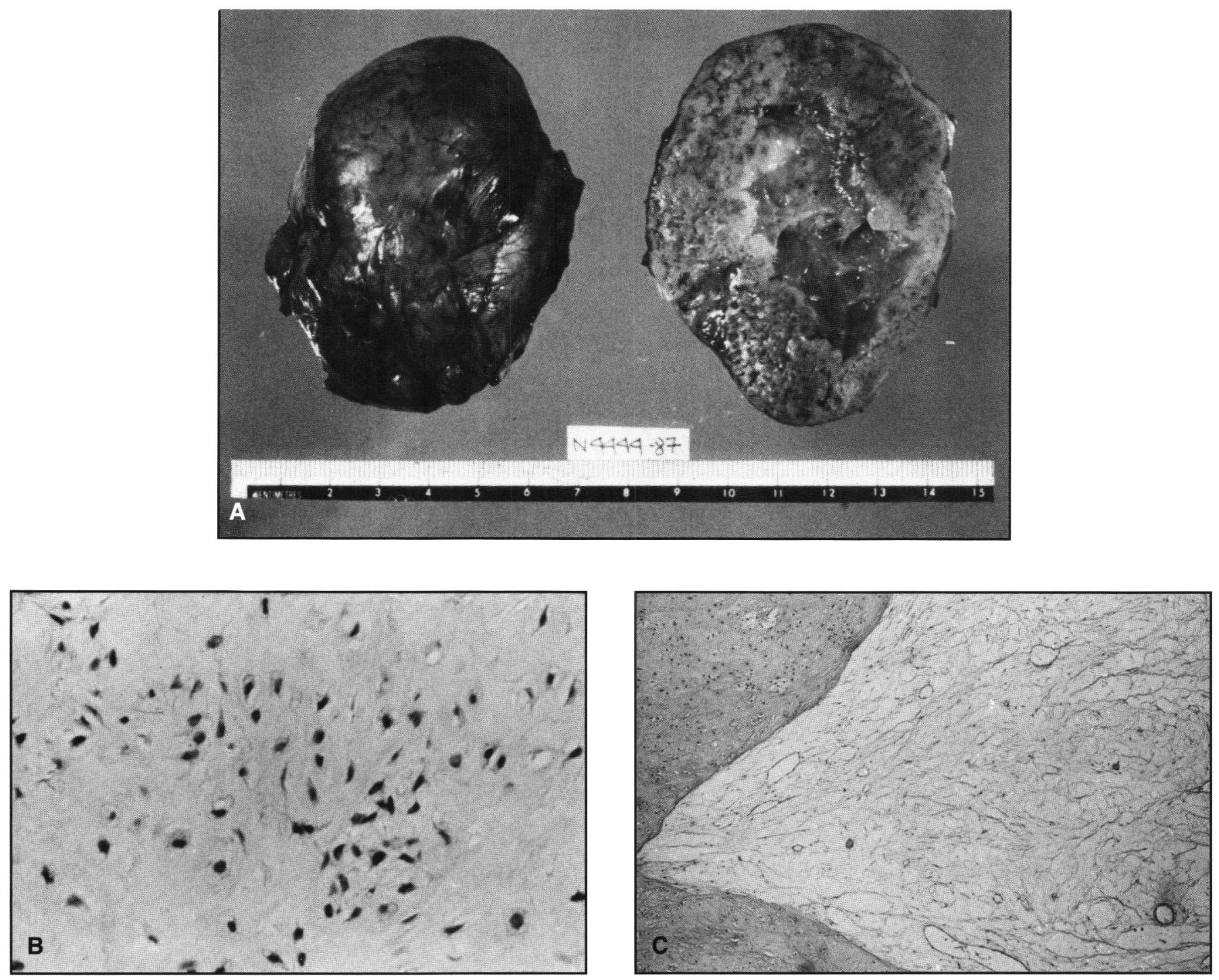

Figure 3: Patient 2. A) Macroscopic appearance of the tumor. Note the central gelatinous part of the tumor. B) Mature hyaline cartilaginous tissue. Lacunae not well developed but no evidence of nuclear atypia or mitosis. $H \& E \times 160$. C) Clear demancation line between the typical cartilaginous tissue and the central loose-textured connective tissue. $H \& E \times 64$.

large size at presentation (mean diameter $6 \mathrm{~cm}$ and mean weight 170 grams) (see Table 2), and their tendency to be localized in the frontoparietal area (Table 1). Three patients died suddenly; the tumor was discovered at autopsy, and was responsible for brain herniation. ${ }^{21,22,28}$

The radiological features can warrant, in some cases, a presumptive pre-operative diagnosis. The findings are summarized in Table 3. Calcifications and hyperostosis are frequent on plain skull films. In our analysis of the reported cases, we found two distinct CT-scan presentations (see Table 3). The first pattern or type 1 can be considered "classical". 9,13,14,17,23,25 The second pattern or type 2 , in which there is a hypodense central area, has been reported less frequently. ${ }^{11.15 .20 .37} \mathrm{~A}$ pathological correlation with this second pattern was made in one case and showed that the hypodense central part contained "central cystic degeneration"." Pathological data in our Patient 2 demonstrated that this central area was composed of a very loose-textured edematous connective tissue (without evidence of necrosis). Furthermore, this well hydrated tissue explained the well demarcated hyperintense central area on the long TR MRI sequences. ${ }^{15.37}$ Four cases of benign intradural chondromas imaged with MRI have been reported (including our case), and the findings are summarized in Table 3. The signal either on CT scan or MR scan is often heterogeneous without the typical homogeneous and densely enhancing aspect of a meningioma. On an angiogram, these tumors present as avascular extracerebral space-occupying lesions. ${ }^{11,13,14,24-26,29,37}$ The later is a good distinguishing feature from a meningioma, which is usually associated with a blush on the angiogram. The presence of hypervascularity in an otherwise typical lesion should raise the possibility of a chondrosarcoma. ${ }^{38}$

Surgical resection is the treatment of choice for benign intradural chondromas. These tumors are well demarcated and have no tendency to invade or destroy surrounding parenchyma, and recurrence is rare after total removal. Our two patients remain asymptomatic and without radiological evidence of recurrence, with a follow-up of 6 and 7 years, respectively. The 
Table 1: Reported locations of intracranial chondromas*.

$$
\begin{aligned}
& \text { 1. Meninges: } 34(72 \%) \\
& \text { Convexity: } 19 \\
& \text { Frontal/Parietal: } 17 \\
& \text { others: } 2 \\
& \text { Falx: } 15 \\
& \text { Frontal/Parietal: } 14 \\
& \text { others: I }
\end{aligned}
$$

2. Intracerebral: $7(15 \%)$ Frontal/Parietal: 3 Temporal: 2 Parieto-occipital: 2

3. Choroid Plexus/Intraventricular: 6(13\%)

Lat Ventrical: 4

IIIrd Ventrical: 1

IVth Ventrical:

* Total number of cases: 47 .

long term prognosis is very good with prolonged survival following excision. ${ }^{12,16}$ On the other hand the malignant counterpart, the chondrosarcoma, has a variable clinical course with frequent recurrences and occasional distant osseous and visceral metastatic spread, particularly with the mesenchymal sub-type of chondrosarcoma..$^{33.38-40}$

Usually, benign cartilaginous tumors can be differentiated from the malignant counterpart on the basis of histopathological criteria. ${ }^{41-44}$ A benign chondroma has an expansile and noninfiltrative pattern of growth and typically contains well differentiated cartilaginous cells within lacunae, with a low cellularity, and no mitoses. ${ }^{42}$ However, the degree of differentiation is situated along a continuum and the distinction between a benign chondroma and a low-grade chondrosarcoma is sometimes not obvious. The criteria to diagnose a low-grade (grade 1) chondrosarcoma are based mostly on the morphology of the
Table 2: General features intradural chondromas*.

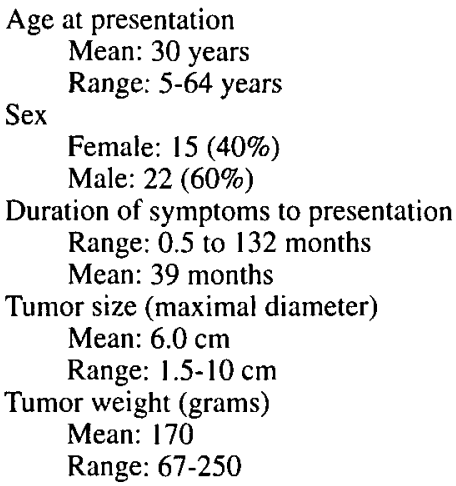

* Sufficient clinical information was available in 37 published cases.

nuclei in the tumor chondrocytes, and include the presence of numerous multiple ( 2 or more) nuclei within one lacuna and the exclusive presence or marked preponderance of small and densely-staining nuclei. ${ }^{41}$ In some cases, a small number of larger and somewhat pleomorphic nuclei are present in isolated areas. ${ }^{41}$ Sanerkin emphasizes invasiveness as a reliable guide. ${ }^{44}$ Dense cellularity, presence of significant numbers of larger nuclei and mitotic figures are not features of grade 1 chondrosarcoma (if present, indicate higher grade) ${ }^{41}$ Some diagnostic difficulties can arise because some cartilage neoplasms, both benign and malignant, contain myxoid areas in which characteristic chondrocytes are not apparent. ${ }^{43}$

The higher grades (2 and 3) contain more striking features (mitotic figures, necrosis, marked anisokaryosis, multinucleate cells) and are easy to identify. ${ }^{41,44}$ However, any chondrosarcoma can contain areas of very well differentiated chondroid tisssues,

Table 3: Radiological features

\begin{tabular}{lll}
\hline Modality & Findings & Comments \\
\hline Skull X-Ray & $\begin{array}{l}\text { Calcifications: } \\
\text { Usually dense or mottled } \\
\text { Rarely shell-like or curvilinear }\end{array}$ & Inner table hyperostosis reported in 8 Cases (13,17,19,42) \\
\hline CT Scan & $\begin{array}{l}\text { Huge calcified mass } \\
\text { Type } 1\left(^{*}\right) \\
\text { mixed density signal } \\
\text { minimal to moderate enhancement } \\
\text { Type 2 (II) } \\
\text { hypodense well defined central area } \\
\text { with hyperdense enhancing peripheral part }\end{array}$ & $\begin{array}{l}\text { Calcifications; no reported case without calcification on CT scan } \\
\text { No or minimal surrounding oedema }\end{array}$ \\
\hline MRI & $\begin{array}{l}\text { Mixed intensity signal } \\
\text { Predominantly hypointense on T1 spin-echo and } \\
\text { hyper-intense on T2 spin-echo } \\
\text { Enhancement minimal to moderate except for more } \\
\text { intense enhancement within peripheral part in type 2 } \\
\text { (ring enhancement). (\&) }\end{array}$ & $\begin{array}{c}\text { Distinctive pattern: well defined central part with high intensity signal } \\
\text { in T2 (Patient \#2): corresponding to CT scan type 2 }\end{array}$ \\
\hline $\begin{array}{l}\text { Avascular extracerebral lesion } \\
\text { Angiography }\end{array}$ & $\begin{array}{l}\text { The presence of hypervascularity in an otherwise typical lesion should } \\
\text { raise the possibility of a chondrosarcoma }\end{array}$ \\
\hline
\end{tabular}

(*); Based on references $9,13,14,17,23,25$.

(II); Based on references $11,15,20,37$

(\&); Based on references $9,15,25$ 
and this emphasizes the need for the extensive and meticulous examination of the pathological specimen, which is mandatory before a definite diagnosis of benign chondroma is made. ${ }^{43}$ Benign intracranial intradural chondromas seem to have very little tendency for malignant transformation. ${ }^{8}$ Accordingly, a tumor first diagnosed as a "benign" chondroma but showing rapid recurrence, invasion or metastasis should be suspected of being a chondrosarcoma. In such a situation, it is very likely that a benign section of a chondrosarcoma was investigated initially. ${ }^{42}$

The authors have presented two cases of intradural chondroma. These rare cartilaginous tumors have a particularly benign course, present usually at a younger age than meningioma, and without sex predominance. The pre-operative diagnosis can be made, on the basis of some radiologic features that are suggestive, despite the rarity of such a neoplasm. The treatment is surgical excision usually with good results and no recurrence. This benign tumor can be distinguished in most cases from its malignant conterpart, the chondrosarcoma. There is no reported case of malignant transformation of an intradural benign cartilaginous tumor.

\section{REFERENCES}

1. Berkmen YM, Blatt ES. Cranial and intracranial cartilaginous tumors. Clin Radiol 1968; 19: 327-333.

2. Zulch KJ, Wechsler W. Pathology and classification of gliomas. Prog Neurol Surg 1968; 2: 1-84.

3. Gabrielsen TO, Kingman AF. Osteocartilaginous tumors of the base of the skull. Am J Roentgenol Radium Ther Nucl Med 1964; 91 : 1016-1023.

4. Minagi $\mathrm{H}$, Newton TH. Cartilaginous tumors of the base of skull. Am J Roentgenol Radium Ther Nucl Med 1969; 105: 308-313.

5. Russell DS, Rubinstein LJ. Pathology of Tumors of the Nervous System. 5th ed. Baltimore, Williams \& Wilkins, 1989.

6. Sarwar M, Swischuk LE, Schechter MM. Intracranial chondromas. Am J Roentgenol 1976; 127: 973-977.

7. Acampora S, Troisi F, Fusco G, Del Gaizo S. Voluminous intracranial chondroma. Surg Neurol 1982; 18: 254-257.

8. Alpers BJ. Cerebral osteochondroma of dural origin. Ann Surg 1935; 101: 27-37.

9. Beck DW, Dyste GN. Intracranial osteochondroma: MR and CT appearance. Am J Neuroradiol 1989; 10 (Suppl.): 7-8.

10. Burger PC, Scheithauer BW, Vogel FS. Surgical Pathology of the Nervous System and its Coverings. 2. The Intracranial Meninges. 3rd ed. Churchill Livingstone, 1991, pp 96-116.

11. Hadadian K, Abtahii H, Asil Z, Rakhshan M, Vessal P. Cystic falcine chondroma: case report and review of the literature. Neurosurgery 1991; 29: 909-912.

12. Hardy RW, Benjamin SP, Gardner WJ. Prolonged survival following excision of dural chondroma. J Neurosurg 1978; 48: 125-127.

13. Mapstone TB, Wongmongkolrit T, Roessman U, Ratcheson RA. Intradural chondroma: a case report and review of the literature. Neurosurgery 1983; 12: 111-114.

14. Matz S, Israeli Y, Shalit MN, Cohen ML. Computed tomography in intracranial supratentorial osteochondroma. J Comput Assist Tomogr 1981; 5: 109-115.

15. Nakazawa T, Inoue T, Suzuki F, Nakasu S, Handa J. Solitary intracranial chondroma of the convexity dura: case report. Surg Neurol 1993; 40: 495-498.
16. Ozgen T, Pamir MN, Akalan N, Bertan V, Onol B. Intracranial solitary chondroma. J Neurosurg 1984; 61: 399-401.

17. Sebbag M, Schmidt V, Leboucq N, et al. Chondrome dure-mérien; a propos d'un cas et revue de la littérature. J Radiol 1990; 71: 495498.

18. Siris JH, Angrist A. Chondroblastic meningiomas. Am J Surg 1942; 57: 162-167.

19. Wu WQ, Lapi A. Primary non-skeletal intracranial cartilaginous neoplasms: report of a chondroma and a mesenchymal chondrosarcoma. J Neurol Neurosurg Psychiatry 1970; 33: 469-475.

20. Yang PJ, Seeger JF, Carmody RF, Fleischer AS. Chondroma of falx: CT findings. J Comput Assist Tomogr 1986; 10: 1075-1076.

21. Hirvonen J, Heikinheimo H. A case of intracranial chondroma: a case report. Acta Pathol Microbiol Scand 1979; 76: 19-24.

22. Letterer E. Uber heterotope Geschwulste der Aderhautgeflechte. Beitr Pathol Anat 1920; 67: 370-415.

23. Salazar J, Vaquero J, Aranda IF, et al. Choroid plexus papilloma with chondroma: case report. Neurosurgery 1986; 18: 781-783.

24. Siqueira EB, Bucy PC. Case report: chondroma arising within a mixed glioma. J Neuropathol Exp Neurol 1966; 25: 667-673.

25. Valdueza JM, Freckmann N, Herrmann HD. Chondromatosis of the choroid plexus: case report. Neurosurgery 1990; 27: 291-294.

26. Ahyai A, Sporri O. Intracerebral chondroma. Surg Neurol 1979; 11: 431-433.

27. Chorobski J, Jarzymski J, Ferens E. Intracranial solitary chondroma. Surg Gynecol Obstet 1939; 68: 677-686.

28. Jakob C, Pedace EA. Fibro-condro-osteoma primitivo des cerebro. Archivos Argentinos de Neurologia 1933; 9: 13-20.

29. Rubinstein LJ. The development of contiguous sarcomatous and gliomatous tissue in intracranial tumors. J Pathol Bact 1956; 71 : 441-459.

30. Enzinger FM, Weiss SW. Soft Tissue Tumors. 2nd ed. C.V. Mosby, 1988.

31. Dutton J. Intracranial solitary chondroma. J Neurosurg 1978; 49: 460-463.

32. Russell DS. Meningeal tumours: a review. J Clin Pathol 1950; 3: 191-211.

33. Sheithauer BW, Rubinstein LJ. Meningeal mesenchymal chondrosarcoma. Report of 8 cases and review of the literature. Cancer 1978; 42: 2744-2752.

34. Katayama Y, Tsubokawa T, Maejima S, Satoh S, Sawada T. Meningeal chondrosarcomatous tumor associated with meningocytic differentiation. Surg Neurol 1987; 28: 375-380.

35. Kepes JJ, Rubinstein LJ, Chiang $\mathrm{H}$. The role of astrocytes in the formation of cartilage in gliomas. An immunohistochemical study of four cases. Am J Pathol 1984; 117: 471-483.

36. Quest, DO. Meningiomas: an update. Neurosurgery 1978; 3: 219-225.

37. Kretzschmar HA, Eggert HR, Beck U, Furmaier R. Intracranial chondroma: case report. Surg Neurol 1989; 32: 121-125.

38. Hassounah M, Al-Mefty O, Akhtar M, Jinkins JR, Fox JL. Primary cranial and intracranial chondrosarcoma: a survey. Acta Neurochir 1985; 78: 123-132.

39. Heros RC, Martinez AJ, Ahn HS. Intracranial mesenchymal chondrosarcoma. Surg Neurol 1980; 14: 311-317.

40. Salcman M, Scholtz H, Kristt D, Numaguchi Y. Extraskeletal myxoid chondrosarcoma of the falx. Neurosurgery 1992; 31: 344-348.

41. Evans HL, Ayala AG, Romsdahl MM. Prognostic factors in chondromsarcoma of bone: a clinicopathologic analysis with emphasis on histologic grading. Cancer 1977; 40: 818-831.

42. Krayenbuhl H, Yasargil M. Chondromas. Prog Neurol Surg 1975; 6: 435-463.

43. Meachim G. Editorials and annotations: histological grading of chondrosarcoma. J Bone Joint Surg (Br) 1979; 61b: 393-394.

44. Sanerkin NG. The diagnosis and grading of chondrosarcoma of bone: a combined cytologic and histologic approach. Cancer 1980; 45: 582-594. 